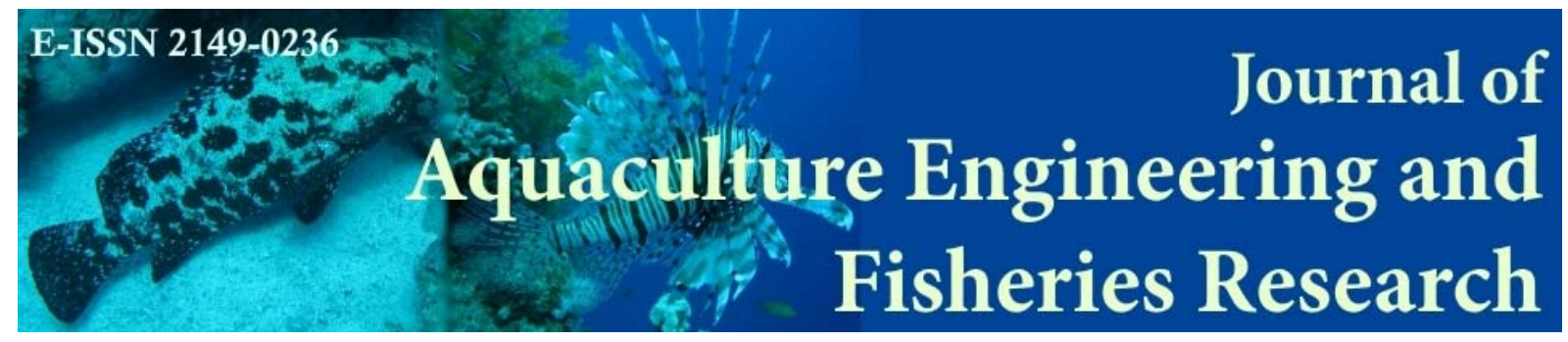

ORIGINAL ARTICLE/ORİJİNAL ÇALIŞMA

FULL PAPER

TAM MAKALE

\title{
MICROSATELLITE AND ALLOZYME VARIATIONS IN STARLET STURGEON WILD BROODSTOCK AND HATCHERY-PRODUCED OFFSPRING, USED FOR RESTOCKING OF LOWER DANUBE RIVER
}

Petya P. Ivanova ${ }^{1}$ ORCID ID: $\underline{0000-0001-5892-2479}$, Nina S. Dzhembekova ${ }^{1}$ ORCID ID: $\underline{0000-0001-9620-}$
$\underline{6422}$, Velichka Kardjeva ${ }^{2}$ ORCID ID: $\underline{000-0003-3707-1438}$, Angel G. Tsekov ${ }^{3}$ ORCID ID: $\underline{0000-0002-}$
$\underline{4581-4484}$, Violin S. Raykov
${ }^{1}$ Institute of Oceanology, BAS, Varna, Bulgarian
${ }^{2}$ Aquachim JSCo, Sofia, Bulgarian
${ }^{3}$ Plovdiv University P. Hilendarski, Biological Faculty, Department of Ecology and Environmental Protection, Plovdiv, Bulgarian

Received: 05.06 .2017

Accepted: 30.07 .2017

Published online: 30.09.2017
Corresponding author:

Petya IVANOVA, Institute of Oceanology, 40 Parvi Mai str., P.O. Box 152, Varna 9000, Bulgaria

E-mail: pavl petya@yahoo.com

\begin{abstract}
:
The natural population of all sturgeon species has been seriously affected by overexploitation in combination with a substantial loss and degradation of habitats during the $20^{\text {th }}$ information about the genetic identity of the existing fish populations. The genetic pattern of sterlet (broodstock and offspring) were analyzed, using allozymes and seven microsatellite loci (LS19, LS34, LS39, LS54, LS68, Aox45 and Aox27) as markers for species identification. From the seven microsatellite loci three (LS57, Aox23 and Aox45) have shown a tetrasomic profile. The most polymorphic locus for the broodstock was LS-57 with 12 alleles in population, followed by Aox 45, LS-68 and LS-54 with 10 alleles. For offspring, the most polymorphic locus was Aox 23 with 11 alleles. Other loci presented a lower level of polymorphism range between 2 to 8 alleles identified for the analyzed individuals. The average observed and expected heterozygosities were 0.429 and 0.413 in the broodstock and 0.500 and 0.423 in the offspring, respectively. The preliminary data showed that selected allozymes and microsatellite markers allow identification of the stellate sturgeon from Bulgarian farms and could be applied to test and control the broodstocks used for restocking programmes.
\end{abstract}

Keywords: Sterlet, Microsatellite, Allozymes, Identification, Restocking 
Journal abbreviation: J Aquacult Eng Fish Res

\section{Introduction}

Most sturgeon species are near extinction and have been listed in the Appendices to CITES (Convention on International Trade in Endangered Species of Wild Fauna and Flora (Raymakers, 2007). From six sturgeon species distributed in the Lower Danube River, five are supposed to be critically endangered and only one Acipenser ruthenus is classified as vulnerable according to IUCN Red List 2010.

Instead of the five year prohibition (2010-2015) of sturgeon catches in Bulgaria to protect the sturgeon biodiversity, illegal catches in combination with a substantial loss and degradation of habitats are the main causes of decreases in stellate sturgeons stocks and the number of adult spawners.

Genetic-biochemical markers for sturgeon identification (fillet and caviar) were applied for the Bulgarian part of the Lower Danube and the Black Sea (Dobrovolov et al., 2004, Dobrovolov et al., 2005). Sturgeon hybrids were determined on morphological and genetic level in Bulgarian Black Sea waters and the Danube River. Three different hybrids of various offspring generations with participation of Acipenser ruthenus were identified (Tsekov et al., 2008). The increasing presence of natural sturgeon hybrids in the Danube River and the Black Sea is another evidence for decreasing sturgeon stocks. Not only their reproduction is endangered, but also the genotypes of sturgeons are changed. The decreases of natural population and uncontrolled restocking resulting in production of hybrids will decrease natural genetic diversity of sturgeon species in their original distribution area (Havelka et. al., 2011).

Today many molecular methods are available for studying various aspects of wild populations, captive brood stocks and interactions between wild and cultured stocks of fish and other aquatic species (Yudha et al., 2012). Use of molecular data to assess the genetic structure in Danube sturgeon individuals is necessary because a classification as pure species or as hybrids, based only on morphological data can be misleading and inaccurate (Dudu et al., 2011).

The population structure and relationships of sturgeon can be easily identified using microsatellite markers. The application of these methods will allow an appropriate broodstock management both in aquaculture and in sturgeon restocking programmes (Rosenthal et al., 2006).
Between seven and nine microsatellite loci variations were applied for species and hybrids (bester) identification in sterlet sturgeon (Acipenser ruthenus) from the Lower Danube (Dudu et al., 2013; Dudu et al., 2015).

In the case of conservation studies in sturgeons, the microsatellites are useful for the characterization of genetic diversity and structure of populations; selection of breeders introduced in assisted reproduction programmes with the aim of sustaining the wild population by releasing in the river of juveniles resulted in aquaculture conditions from wild genitors (Dudu et al., 2013).

The aim of this study was to examine the genetic variability of Acipenser ruthenus broodstock and offspring using seven microsatellite DNA markers and allozymes, considering its possible application for further restocking programs of the Bulgarian part of the Lower Danube.

\section{Materials and Methods}

\section{Microsatellites}

Fin clips were collected from 14 Acipenser ruthenus individuals (brood stock and offspring), captured in 2014-2015 from aquaculture (sturgeon farm"Fishinvest", Montana, Bulgaria), doing restocking of the Bulgarian part of Danube. Sterlet brood stock samples were caught in May 2014 from the Danube River (Belene region, river $\mathrm{km}$ 505-565) from the wild population and breed in a mentioned above sturgeon farm.

Total DNA was extracted from ethanol-preserved fin clips by using „Omega Bio-tek”, E.Z.N.A. Tissue DNA Kit (D3396-10, USA). For PCR amplification seven primer pairs: LS19, LS34, LS54, LS59, LS68, Aox 23 and Aox45, tested for NorthAmerican sturgeons and sterlet in the Lower Danube (Dudu et al., 2013) were used (Table 1) for fragment analyses.

Two multiplex PCR reactions were performed: a 4-plex reaction for LS-19, LS-34, LS-57 and LS68, and a 3-plex reaction for LS-54, Aox 23 and Aox 45. For microsatellite loci detection, we used the forward primers labeled with four different fluorescent dyes: PET, VIC, 6-FAM and NED.

Multiplex PCR reactions were carried out in a 20 $\mu \mathrm{L}$ final volume with the following reaction components: $10 \mu \mathrm{l}$ PCR Mastermix (Bioneer), primers ( $1 \mu \mathrm{L}$ from each primer), $2 \mu \mathrm{L}$ target DNA and ultrapure water to reach the final volume. 
PCR amplifications were performed in gradient PCR (Swift MaxPro Thermal Cycler), using the following program: a first denaturation step at $95^{\circ} \mathrm{C}$ for 10 minutes, 40 cycles of denaturation at $95^{\circ} \mathrm{C}$ for 30 seconds, annealing at $55^{\circ} \mathrm{C}$ for $30 \mathrm{sec}-$ onds, and extension at $72^{\circ} \mathrm{C}$ for 60 seconds and a final extension step at $72^{\circ} \mathrm{C}$ for 20 minutes. After amplification the PCR products were tested on $2 \%$ agarose gel.

The length of amplified fragments were determined using an Applied Biosystems Genetic Analyzer $\mathrm{AB} 3130$. The analyses of sample data were performed using the GeneMapper v.4 software. Calculation of the observed and expeted heterozygosity and $\mathrm{F}_{\mathrm{ST}}$ was prepared using Genalex software (Peakall \& Smouse, 2012).
Allozymes: For electrophoretic analyses, the samples were stored at $-20^{\circ} \mathrm{C}$ until the analyses in the laboratory. For analysis of the esterases (EC 3.1.1.1-EST) and general muscle proteins (PROT), a homogenate of white dorsal muscle was used. The proteins were separated by horizontal starch gel electrophoresis (Dobrovolov, 1973). The staining of different enzymes was performed as previously decribed (Shaw \& Prasad, 1970). The buffer systems (Dobrovolov, 1976) were used for the electrophoresis. The nomenclature of loci and alleles used here followed essentially previously published recommendations (Shaklee et al., 1990).

Table 1. Primer sequences

\begin{tabular}{|l|l|}
\hline Locus & Primer sequences (5'-3') \\
\hline LS-19 & F:6 FAM catcttagccgtctgtggtac \\
& R: caggtccctaatacaatggc \\
\hline LS-34 & F: VIC-tacataccttctgcaacg \\
& R: gatcccttctgttatcaac \\
\hline LS-54 & F: NED- ctctagtctttgttgattacag \\
& R: caaaggacttgaaactagg \\
\hline LS-57 & F: PET-gcttggttgctagtttgc \\
& R: gtacagtatgagaccacaggc \\
\hline LS-68 & F: NED-ttattgcatggtgtagctaaac \\
& R: agcccaacacagacaatatc \\
\hline Aox23 & F:6FAM-cagtgtgctagcttctcaata \\
& R: gttagcttaaccatgaattgtg \\
\hline Aox45 & F: PET-ttgtccaatagtttccaacgc \\
& R: tgtgctcctgcttttactgtc \\
\hline
\end{tabular}

\section{Results and Discussion}

Restocking with sturgeon fishes has been fulfilled in the Bulgarian section of the Danube River since 1998 and continued to 2005 (data from MoEW). The species used for this purposes were Acipenser guildenstaedti (506 873 numbers, by weight of 19 to 280 grams), Huso huso (38 950 numbers, 5 to 350 grams) and Acipenser ruthenus (1 300 numbers, 50 to 180 grams) (Table 2).

Nowadays restocking programs were renewed with the introduction of the Acipenser ruthenus samples in 2014 and 2015 in the Lower part of the Danube River. According to this program in October 2014 on Danube river km 565, 10523 samples were restocked. During June 2015 totally 40660 samples were restocked on the 743 and 369 river $\mathrm{km}$.

\section{Genetic-Biochemical Data}

The samples were tested for species identity using first biochemical genetical markers pointed for sturgeon species (Dobrovolov et al., 2005). Analyses of (PROT) showed ten monomorphic zones, species specific for sterlet (broodstock and offspring), (Figure 1A). Electrophoretical spectra on the samples analyzed were typical for sterlet described earlier (Dobrovolov et al., 2005; Tsekov et al., 2008). Esterases were polymorphic with two esterases zones, but they did not show species diversity (Figure 1B). The polymorphism observed could be used as a marker for identification of sterlet populations (Acipenser ruthenus). 
Journal of Aquaculture Engineering and Fisheries Research, 3(4): 199-206 (2017)

Journal abbreviation: J Aquacult Eng Fish Res

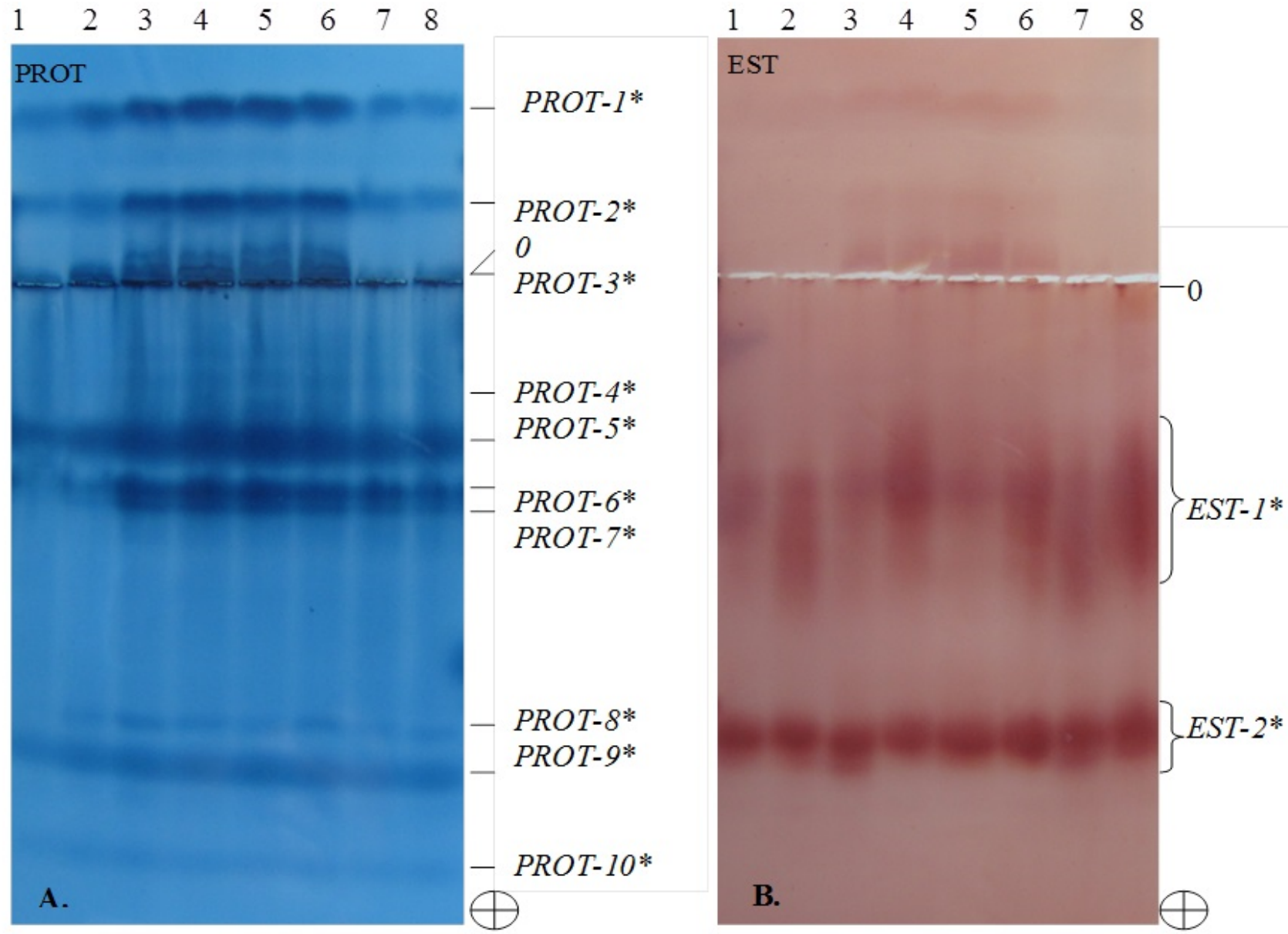

Figure 1. A. Electrophoregrams on general muscle proteins (PROT) and B. general unspecified esterases (EST) on Acipenser rutenus, 1-4- broodstock, 5-8 - offspring, 0 - origin.

Table 2. Aquaculture produced sturgeon fingerlings released in Danube River for (1998-2005)

\begin{tabular}{|c|c|l|c|c|c|c|c|}
\hline Year & $\begin{array}{c}\text { Total } \\
\text { number }\end{array}$ & $\begin{array}{c}\text { Acipenser } \\
\text { gueldenstaedti }\end{array}$ & $\begin{array}{c}\text { Average } \\
\text { weight (g) }\end{array}$ & $\begin{array}{c}\text { Huso } \\
\text { huso }\end{array}$ & $\begin{array}{c}\text { Average } \\
\text { weight (g) }\end{array}$ & $\begin{array}{c}\text { Acipenser } \\
\text { rutenus }\end{array}$ & $\begin{array}{c}\text { Average } \\
\text { weight (g) }\end{array}$ \\
\hline $\mathbf{1}$ & $\mathbf{2}$ & $\mathbf{3}$ & $\mathbf{4}$ & $\mathbf{5}$ & $\mathbf{6}$ & $\mathbf{7}$ & $\mathbf{8}$ \\
\hline 1998 & 1500 & 1000 & 250 & 200 & 300 & 300 & 180 \\
\hline 1999 & 30100 & 27400 & 230 & 2700 & 320 & - & - \\
\hline 2000 & 21150 & 20400 & 200 & 750 & 350 & - & - \\
\hline 2001 & 28100 & 28100 & 200 & - & - & - & - \\
\hline 2002 & 23530 & 22530 & 280 & - & - & 1000 & 50 \\
\hline 2003 & 166617 & 161317 & 82 & 5300 & 5 & - & - \\
\hline 2004 & 211126 & 211126 & 18,87 & - & - & - & - \\
\hline 2005 & 65000 & 35000 & 15 & 30000 & 15 & - & - \\
\hline Total & $\mathbf{5 4 7 1 2 3}$ & $\mathbf{5 0 6 8 7 3}$ & - & $\mathbf{3 8 9 5 0}$ & - & $\mathbf{1 3 0 0}$ & - \\
\hline
\end{tabular}

On the base of morphological and genetic data three different sturgeon hybrids with participation of sterlet (Acipenser gueldenstaedti x Acipenser ruthenus, Acipenser stellatus $\mathrm{x}$ Acipenser ruthenus, Huso huso x Acipenser ruthenus) were described along the Bulgarian Black Sea coast and the Danube river (Tsekov et al., 2008). Electrophoretical data on the sterlet samples analyzed did not show hybrid spectra. 


\section{Microsatellite Data}

In this study, we have successfully amplified all seven species specific microsatellite loci for Acipenser ruthenus (Figure 2A - D). The loci LS57, Aox23and AoX45 are considered to be tetrasomic, while the loci LS-19, LS-34, LS-54 and LS-68 are considered to have a disomic profile (Fig 2A-D). The same pattern of each microsatellite locus were pointed for the sterlet species (Dudu et al., 2013).
A

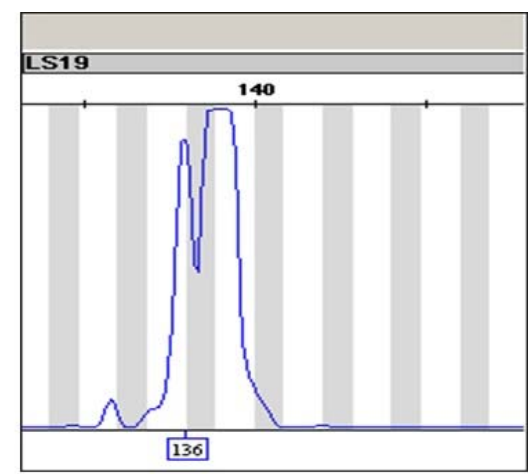

B

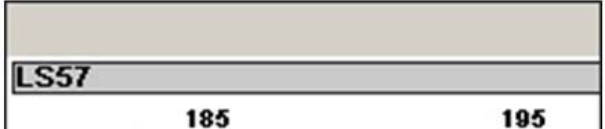

C
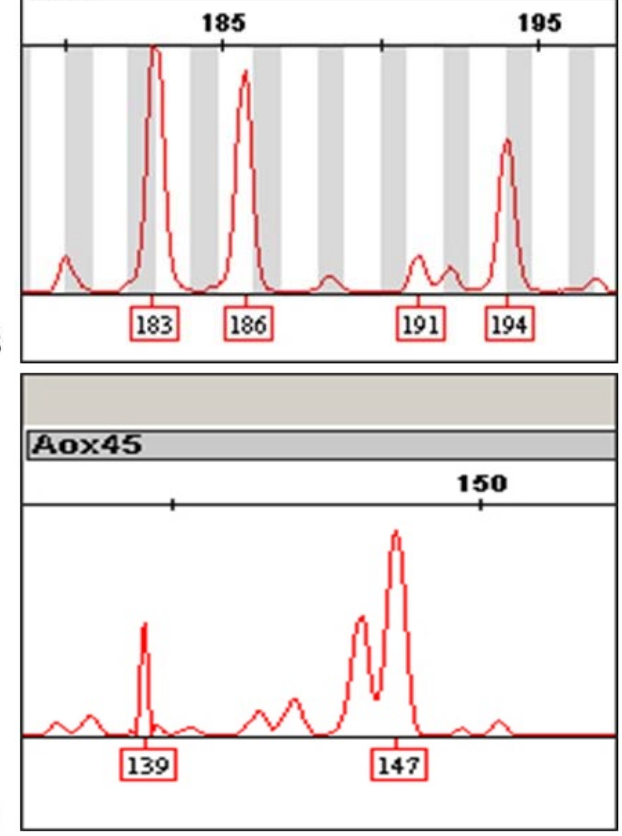
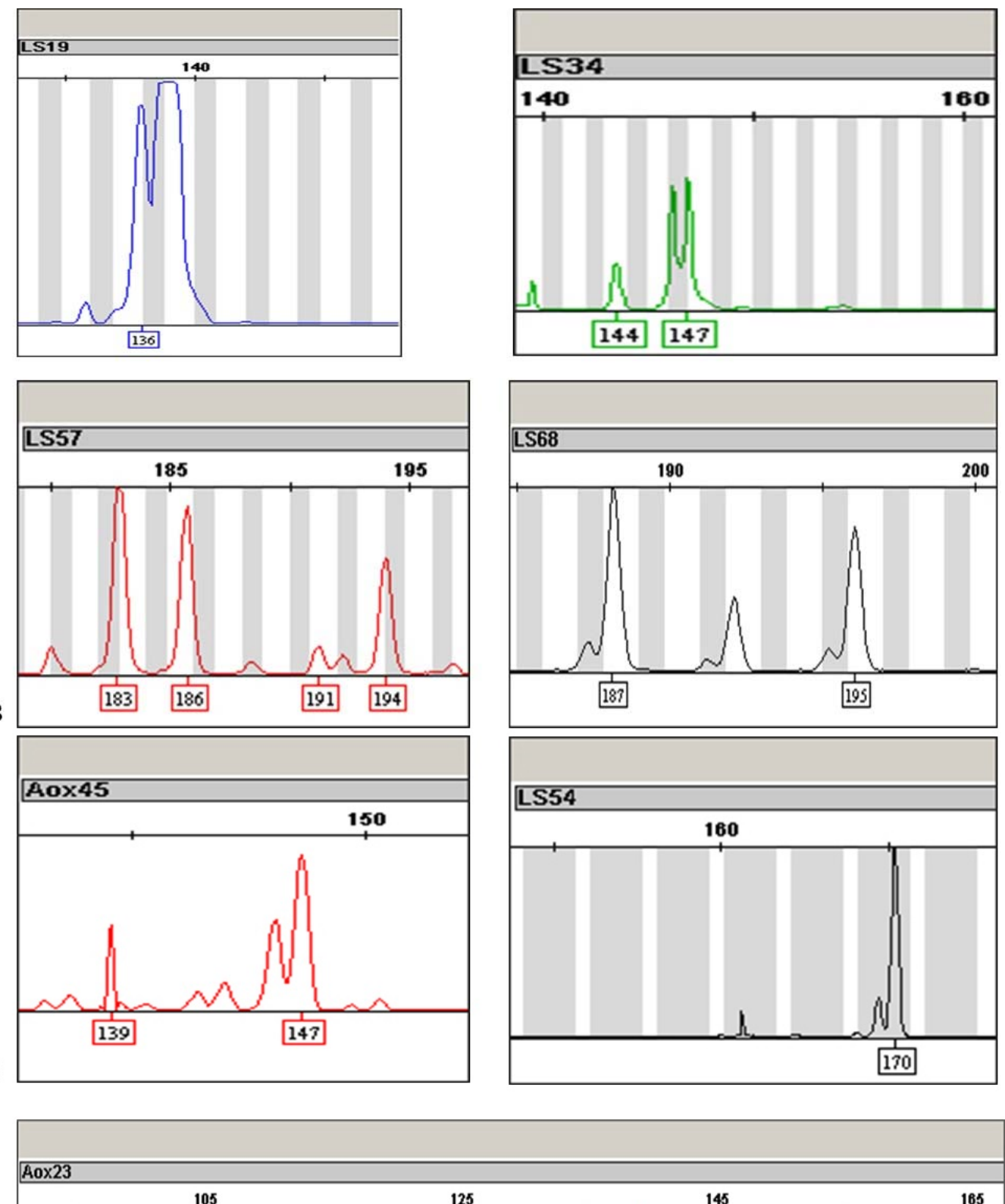

D

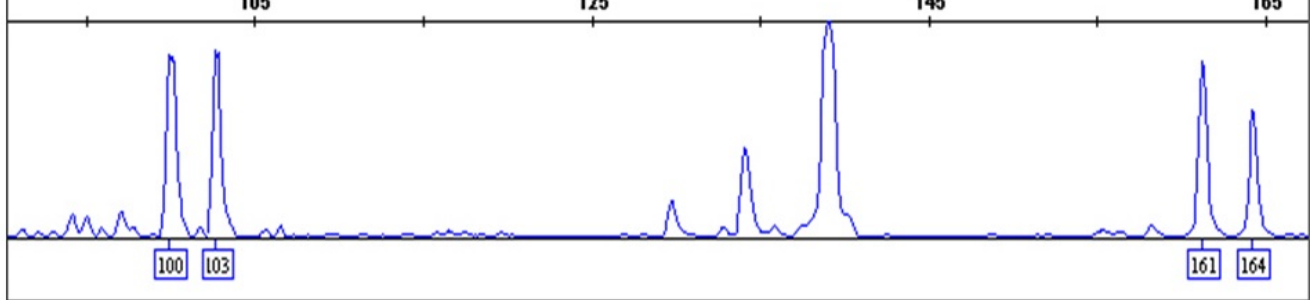

Figure 2. Electrophoretic profiles in Acipenser ruthenus for: A. LS-19 and LS-34; B. LS-57 and LS68; C. Aox 45 and LS-54; D. Aox 23. 
Genotypes were determined for all individuals. The number of allele peaks depends on the level of ploidity of the analyzed species and on whether the individual tested is heterozygote or homozygote.

All seven loci presented polymorphic profile. The size of the alleles at individual loci varied between $68-209$ bp. For the broodstock a high level of polymorphism was observed for LS-57 - 12 alleles in range of 130-203 bp, 10 alleles of 125-209 bp for LS-54, LS-68 and Aox 45. For offspring a high level polymorphism was observed for Aox 23 - 11 alleles in range 100-185 bp. Other loci (LS-19, Aox23, LS-34 for broodstock and LS-19, LS-54, LS-68, LS-34, LS-57 and Aox 45 for offspring) present a lower polymorphism in population, only 2 to 8 alleles being identified for all individuals. The size of the alleles (bp) and the number of alleles of each locus are presented in Table 3.

The heterozigosity is among the most important statistical values that can offer essential information about the diversity and history of the population, stock or aquaculture strain. The loci LS57, Aox 23 and Aox 45 are considered to be tetrasomic, while the loci LS-19, LS-34, LS-54 and LS-68 are considered to have a disomic profile (Dudu et al., 2013).
For the disomic loci the assessment of the genetic variability was realized by determining the values of observed $\left(\mathrm{H}_{\mathrm{O}}\right)$ and estimated heterozygosity $\left(\mathrm{H}_{\mathrm{E}}\right)$.The values of Ho for Acipenser ruthenus (broodstock and offspring) 0,429 and 0,500 were a little bit higher than these of expected heterozigosity (He) - 0,413 and 0,423 (Table 4). $\mathrm{F}_{\mathrm{ST}}$ was calculated $(-0,002)$ and indicated no differentiation between the populations.

The analysis of a higher number of loci and individuals will provide more precise information of the genetic diversity by means of nuclear markers. Analyses of microsatellites and mtDNA could be used for identification of hybrids and the purestock of sturgeon species (Burcea et al., 2014). The application of these methodologies at fish farms would allow to precise species identification, avoiding the usage of hybrids in reproduction and repopulation programs, that might lead to the alteration of the native populations.

The multiplex PCR reaction is a good method for evaluation of intraspecific genetic diversity used for the first time in Bulgaria for this species and allow characterizing the genetic variation of the sturgeon.

Table 3. The size of the alleles (bp) and $\mathrm{N}$ (number of alleles of each locus) analyzed on A. rhutenus (broodstock and offspring).

\begin{tabular}{|c|c|c|c|c|}
\hline \multirow{2}{*}{ Locus } & \multicolumn{2}{|c|}{ Broodstock } & \multicolumn{2}{c|}{ Offspring } \\
\cline { 2 - 5 } & Size & N & Size & N \\
\hline LS-19 & $130-139$ & 5 & $130-139$ & 2 \\
\hline Aox 23 & $100-185$ & 7 & $100-185$ & 11 \\
\hline LS-54 & $160-170$ & 10 & $160-170$ & 8 \\
\hline LS-68 & $162-209$ & 10 & $162-209$ & 8 \\
\hline LS-34 & $68-188$ & 5 & $68-188$ & 6 \\
\hline LS-57 & $130-203$ & 12 & $130-203$ & 7 \\
\hline Aox45 & $125-147$ & 10 & $125-147$ & 7 \\
\hline
\end{tabular}


Journal abbreviation: J Aquacult Eng Fish Res

Table 4. Genetic diversity in sterlet broodstock and offspring

\begin{tabular}{|l|c|c|c|c|}
\hline Locus & \multicolumn{2}{|c|}{ Broodstock } & \multicolumn{2}{c|}{ Offspring } \\
\hline \multirow{2}{*}{ LS 19 } & Ho & He & Ho & He \\
\cline { 2 - 5 } & 0,857 & 0,490 & 1,000 & 0,500 \\
\hline LS34 & 0,286 & 0,490 & 0,286 & 0,490 \\
\hline LS54 & 0,143 & 0,337 & 0,429 & 0,459 \\
\hline LS68 & 0,429 & 0,337 & 0,286 & 0,245 \\
\hline Mean & 0,429 & 0,413 & 0,500 & 0,423 \\
\hline
\end{tabular}

The one and same size of the alleles and number of the alleles in each locus for the two groups (broodstock and offspring) were visualized as an evidence for the origin of the offspring. They are included in the size range, marked for Acipenser rhutenus from the Lower Danube (Dudu et al., 2011, Dudu et al., 2013; Dudu et al., 2015), which proved the species identity used for restocking of the Danube River during the 2014-2015. Hybrids were not identified in the samples analyzed using allozymes.

Restocking of sturgeons (Acipencer guildenstaedti, Huso huso and Acipencer rhutenus) into natural populations in Bulgarian part of the Lower Danube River between 1998-2005 were not based on the genetical identification of broodstock and juveniles. Only in 2014 and 2015 introduction of the $A$. rhutenus samples was done after application of molecular markers (allozymes and microsatellites) for species identification to avoid uncontrolled restocking and to ensure the distribution of the native sterlet sturgeon progeny in the Lower Danube.

Microsatellite analysis is a useful method for species identification of sturgeons, which is confirmed with the data, received for Acipenser rhutenus and could be applied for species identification in restocking programs. Such analyses are necessary to issue a permission for restocking the local rivers (Fopp-Bayat et al., 2015).

\section{Conclusions}

Genetic identification on the base of microsatellites and allozymes of the parental samples and their progeny was applied for characterization of the genetic variation in Acipenser rhutenus samples used for restocking purposes of Bulgarian part of the Lower Danube. The data received is important to avoid hybridization and implementation of non-native for the river sturgeons' species as well as to protect the biodiversity of sturgeons in the Lower Danube River.

\section{Acknowledgements}

This study was funded by the project "Application on the activities from the National action plan for improvement of sturgeons state and their protection in Bulgaria", N 5103020-23-666, Operational programme "Environment", 2007-2013.

\section{References}

Burcea, A., Florescu, I., Dudu, A., Georgescu, S., \& Costache, M. (2014). Molecular methods for the detection of natural hybrids in sturgeon populations. Transylvanian Review of Systematical and Ecological Research, 16(1), 65-72.

Dobrovolov I. (1973). Microelectrophoresis on starch gel. Proceeding of Research Institute of Fisheries, 12, 157-162.

Dobrovolov, I. (1976). Multiple forms of lactate dehydrogenase in anchovy (Engraulis encrasicholus L.) from the Black Sea, Sea of Azov and the Atlantic Ocean. Comptes rendus de 
l'Académie bulgare des Sciences, 29, 877880.

Dobrovolov, I., Tsekov, A., Ivanova, P., \& Yankova, M. (2004). Identification on the black cavier of great sturgeon Huso huso and sterlet Acipenser ruthenus (Acipenseridae, Pisces). Journal of Animal Science, XLI(3), 30-32.

Dobrovolov, I., Ivanova, P., \& Tzekov, A. (2005). Genetic-biochemical identification of some sturgeons and their hybrids (Pisces, Acipenseridae). Verhandlungen des Internationalen Verein Limnologie, 29(2), 917-921.

Dudu, A., Suciu, R., Paraschiv, M., Georgescu, S.E., Costach,e M., \& Berrebi, P. (2011). Nuclear markers of Danube sturgeons hybridization. International journal of molecular Sciences, 12, 6796-6809.

Dudu, A., Georgescu, S., Burcea, A., Florescu, I., \& Costache, M. (2013). Microsatellites variation in sterlet sturgeon, Acipenser rhutenus from the Lower Danube. Animal sciences and Biotechnologies, 46(1), 90-94.

Dudu, A., Macarie, R.D., Burcea, A., \& Georgescu, S.E., \& Costache M. (2015). Identification of bester hybrid and its parental species ( $q$ Huso huso Linnaeus, 1758 and $\partial$ Acipenser ruthenus Linnaeus, 1758) by nuclear markers. Animal Science and Biotechnologies, 48(1), 81-85.

Havelka, M., Kašpar, V., Hulák, M., \& Flajšhans, M. (2011). Sturgeon genetics and cytogenetics: a review related to ploidy levels and interspecific hybridization. Folia Zooligica, 60(2), 93-103.

Fopp-Bayat, D., Kuciński, M., Liszewski, T., Teodorowicz, T., Łączyńska, B., \& Lebeda I.
(2015). Genetic protocol of atlantic sturgeon Acipenser oxyrinchus (L.) fry for restocking the Vistula river, Poland. Journal of Survey in Fisheries Sciences, 2(1), 1-10.

Peakall, R. \& Smouse, P.E. (2012). GenAlEx 6.5: genetic analysis in Excel. Population genetic software for teaching and research-an update. Bioinformatics, 28, 2537-2539.

Raymakers, C. (2007). CITES, the Convention on International Trade in Endangered Species of Wild Fauna and Flora: its role in the conservation of Acipenseriformes. Journal of Applied Ichthyology, 22, 53-65.

Rosenthal, H., Pourkazemi, M., \& Bruch R. (2006). The 5th international Symposium on sturgeons. A conference with major emphasis on conservation, environmental mitigation and sustainable use of the sturgeon resources. Journal of Applied Ichthyology, $22,1-4$.

Shaw, C.H.R. \& Prasad R. (1970). Starch gel electrophoresis of enzymes - a comparison of recipes. Biochemical Genetics, 4, 297-320.

Shaklee, J.B., Allendorf, F.W., Morizot, D.C., \& Whit, G.S. (1990). Gene nomenclature for protein-coding loci in Fish, Transactions of American Fisheries Society, 119, 2-15.

Tsekov, A., Ivanova, P., Angelov, M., Atanasova, S., Bloesch, J. (2008). Natural sturgeon hybrids along the Bulgarian Black Sea coast and in the Danube River, Acta Zoologica Bulgarica, 60(3), 311-316.

Yudha, T.A., Jan-Lung, C., \& Jin- Chywan G. (2012). Genetic diversity of Indonesian milkfish (Chanos chanos) using Amplified Fragment Length Polymorphism (AFLP) analysis. African Journal of Biotechnology, 11(13), 3055 -3060. 